\title{
Urabstimmung der FMH Services
}

\author{
FMH Services
}

Verbal über die Urabstimmung der FMH Services zu folgenden Anträgen:

- Genehmigung des Geschäftsberichtes 2004;

- Genehmigung der Jahresrechnung 2004;

- Dechargeerteilung an die Verwaltung.

Publikationsorgan: Schweizerische Ärztezeitung, Ausgabe Nr. 29/30, vom 27. Juli 2005

Stimmabgabetermin: 30. August 2005 bei der Treuhandstelle

Notarielle Aufsicht: Markus Inauen, Notar, 6208 Oberkirch

Auszählungsdatum: Mittwoch, 5. Oktober 2005, ab 8.00 Uhr

Über die drei nachfolgenden Anträge wurde separat abgestimmt. Das Ergebnis der Abstimmung ist folgendes:

\section{Antrag 1}

Möchten Sie dem Antrag der FMH Services Verwaltung, den Geschäftsbericht 2004 zu genehmigen, zustimmen?

Diesem Antrag wird wie folgt zugestimmt:

\begin{tabular}{lr} 
Abgegebene Stimmen & 2285 \\
\hline Leere Stimmen & 17 \\
\hline $\begin{array}{l}\text { Ungültige Stimmen } \\
\text { (kein Absender, keine Unterschrift) }\end{array}$ & 1359 \\
\hline Gültige Stimmen & 909 \\
\hline Absolutes Mehr & 455 \\
\hline Ja-Stimmen & 882 \\
\hline Nein-Stimmen & 27
\end{tabular}

Dem Antrag wird somit grossmehrheitlich zugestimmt.

\section{Antrag 2}

Möchten Sie dem Antrag der FMH Services Verwaltung, die Jahresrechnung 2004 zu genehmigen und den Reingewinn von Fr. 1418 927.- den Reserven zuzuweisen, zustimmen?
Diesem Antrag wird wie folgt zugestimmt:

\begin{tabular}{lr} 
Abgegebene Stimmen & 2285 \\
\hline $\begin{array}{l}\text { Leere Stimmen } \\
\text { Ungültige Stimmen } \\
\text { (kein Absender, keine Unterschrift) }\end{array}$ & 1359 \\
\hline Gültige Stimmen & 908 \\
\hline Absolutes Mehr & 455 \\
\hline Ja-Stimmen & 864 \\
\hline Nein-Stimmen & 44
\end{tabular}

Dem Antrag wird somit grossmehrheitlich zugestimmt.

\section{Antrag 3}

Möchten Sie dem Antrag der FMH Services Verwaltung, der Empfehlung der Revisionsstelle folgend, der Verwaltung Decharge zu erteilen, zustimmen?

Diesem Antrag wird wie folgt zugestimmt:

\begin{tabular}{lr} 
Abgegebene Stimmen & 2285 \\
\hline Leere Stimmen & 18 \\
\hline $\begin{array}{l}\text { Ungültige Stimmen } \\
\text { (kein Absender, keine Unterschrift) }\end{array}$ & 1359 \\
\hline Gültige Stimmen & 908 \\
\hline Absolutes Mehr & 455 \\
\hline Ja-Stimmen & 879 \\
\hline Nein-Stimmen & 29
\end{tabular}

Dem Antrag wird somit grossmehrheitlich zugestimmt.

Der unterzeichnete Notar des Kantons Luzern bestätigt hiermit, dass er bei den Auszählarbeiten, Mittwoch, den 5. Oktober 2005, von 8.00 bis 12.00 Uhr in der Kanzlei Oberkirch, von Anfang bis Ende anwesend war.

Das Ergebnis dieser Urabstimmung wird als vollständig und richtig bestätigt. Das Abstimmungsergebnis wird in der Schweizerischen Ärztezeitung publiziert.

6208 Oberkirch, den 5. Oktober 2005

Der Notar: Markus Inauen 